\title{
The impact of the Endangered Mauritian flying fox Pteropus niger on commercial fruit farms and the efficacy of mitigation
}

\author{
Ryszard Z. Oleksy, Charles L. Ayady, Vikash Tatayah, Carl Jones \\ Jérémy S.P. Froidevaux, Paul A. Racey and Gareth Jones
}

\begin{abstract}
The endemic Mauritian flying fox Pteropus niger is perceived to be a major fruit pest. Lobbying of the Government of Mauritius by fruit growers to control the flying fox population resulted in national culls in 2015 and 2016, with a further cull scheduled for 2018. A loss of c. 38,318 individuals has been reported and the species is now categorized as Endangered on the IUCN Red List. However, until now there were no robust data available on damage to orchards caused by bats. During October 2015-February 2016 we monitored four major lychee Litchi chinensis and one mango (Mangifera spp.) orchard, and also assessed 10 individual longan Dimocarpus longan trees. Bats and introduced birds caused major damage to fruit, with $7-76 \%$ fruit loss (including natural fall and losses from fungal damage) per tree. Bats caused more damage to taller lychee trees ( $>6 \mathrm{~m}$ high) than to smaller ones, whereas bird damage was independent of tree height. Bats damaged more fruit than birds in tall lychee trees, although this trend was reversed in small trees. Use of nets on fruiting trees can result in as much as a 23 -fold reduction in the damage caused by bats if nets are applied correctly. There is still a need to monitor orchards over several seasons and to test non-lethal bat deterrence methods more widely.
\end{abstract}

Keywords Bats, Chiroptera, flying fox, fruit damage, Mauritius, orchard, Pteropus niger, tree netting

Supplementary material for this article is available at https://doi.org/10.1017/Soo30605318001138

\section{Introduction}

$\mathrm{O}$ ld World fruit bats (Family Pteropodidae, Order Chiroptera) are phytophagous and feed almost

Ryszard Z. Oleksy and Charles L. Ayady Ecosystem Restoration Alliance Indian Ocean, St. Pierre, Mauritius

Vikash Tatayah Mauritian Wildlife Foundation, Vacoas, Mauritius

Carl Jones Durrell Wildlife Conservation Trust, Trinity, Jersey

JÉRÉMY S.P. FroIDEVAux University of Bristol, Bristol, UK

Paul A. Racey University of Exeter, Penryn, UK

GARETH Jones (Corresponding author) School of Biological Sciences, Life Sciences Building, University of Bristol, 24 Tyndall Avenue, Bristol BS8 1TQ, UK. E-mail gareth.jones@bristol.ac.uk

Received 21 May 2018. Revision requested 6 July 2018.

Accepted 17 August 2018. First published online 9 November 2018. exclusively on fruits, leaves, nectar and pollen (Fleming \& Kress, 2011). They typically have broad diets and eat a wide range of native, introduced and cultivated plant species (Lobova et al., 2009; Fleming \& Kress, 2011), and they can consume large quantities of fruits $(50-250 \%$ of their body mass daily; Izhaki et al., 1995). Fruit bats are essential for pollination and seed dispersal of at least 289 species of plants, of which 186 provide economically important resources and products (Fujita \& Tuttle, 1991; Lobova et al., 2009; Aziz et al., 2017; Vincenot et al., 2017). However, negative attitudes towards fruit bats are widespread among the general public (Vincenot et al., 2015; Kingston, 2016). Old World fruit bats commonly feed on cultivated fruits, and therefore they are frequently shot, persecuted and even legally culled as agricultural pests (Bumrungsri et al., 2009; Epstein et al., 2009). A study in Madagascar found that the Madagascan rousette Rousettus madagascarensis prefers native and commercially unimportant fruit to commercially farmed fruit, including lychees Litchi chinensis, and maintaining supplies of native fruit may be a way of limiting damage at orchards (Andrianaivoarivelo et al., 2012).

The Mauritian flying fox Pteropus niger is endemic to the Mascarene Islands (the large islands of Mauritius, Réunion and Rodrigues and nearby smaller islets in the south-west Indian Ocean), and in the past occurred throughout the archipelago. However, it is restricted now to the island of Mauritius (with records of a few individuals on Réunion Island) as a result of habitat destruction and hunting (Cheke \& Dahl, 1981; Cheke \& Hume, 2008). The species plays a disproportionately large ecological role as a seed disperser on Mauritius, especially in dispersing the seeds of large trees that are important in forest canopies (Florens et al., 2017).

In 1974 the population of $P$. niger was estimated to comprise 10,00o individuals (Cheke \& Dahl, 1981). Its range is limited by habitat destruction and it is negatively affected by tropical cyclones, which can potentially decimate populations (Cheke \& Dahl, 1981; Pierson et al., 1996; Grant et al., 1997; Cheke \& Hume, 2008). In common with many bat species it typically produces only a single offspring each year, and occasionally twins, and therefore recovery after decline is slow. The bats have been protected by law since 1983 , when hunting them for food and sport shooting, once a common practice, was made illegal. The population had increased to an estimated 100,000 by 2015 (Republic of 
Mauritius, 2016, 2017), although this estimate was based on disturbance counts, which are considered to be inaccurate and often result in double counting. In 2016 the population was estimated to comprise $62,500( \pm 7 \%)$ individuals (Kingston et al., 2018). Increasingly, there are claims that the bats are damaging commercial fruit crops. Mauritian fruit growers estimate that fruit bats eat $50,000 \mathrm{~kg}$ of lychees per annum and such damage is increasing at a rate of $10 \%$ annually. It is estimated that $10-35 \%$ of fruit in orchards is damaged and, depending on market price and levels of depredation, the cost of this damage can amount to MUR 180 million (USD 5.24 million) annually. Mauritius produces $>42$,000 tonnes of fruit annually from 3,000 ha, with lychees contributing 1,000-4,000 tonnes. An estimated 200-330 tonnes of lychees, worth MUR 45-50 million (USD 1.3-1.45 million), are exported annually (Agricultural Research and Extension Unit of the Food and Agricultural Research Council, pers. comm.; Republic of Mauritius, 2016).

Fruit growers have lobbied the Mauritian Government since 2002 (D. Sarjua, in litt. to Ministry of Agriculture, 18 December 2002, copied to Mauritian Wildlife Foundation) to remove the legal protection for $P$. niger so that it may be controlled in orchards. In 2015 this lobbying was successful, a cull was implemented and the official number of bats killed was 30,938 , followed in 2016 by a further cull of 7,350 bats in an attempt to limit the damage caused to lychee and mango farms (Republic of Mauritius, 2017). The cull commenced despite the lack of clear evidence of the damage caused by the Mauritian flying fox to orchard fruit (Florens, 2015). As a consequence of the culling, ongoing habitat loss and vulnerability to cyclones, $P$. niger was recategorized from Vulnerable to Endangered on the 2018 IUCN Red List, based on an estimated population decline of 50\% in 2015 and 2016, and a projected decline of $>50 \%$ during $2015-$ 2035 (Kingston et al., 2018). A further cull of $20 \%$ of the remaining population has been announced for 2018, and bats continue to be hunted illegally, with an estimated 5,0006,000 individuals killed annually (Kingston et al., 2018).

In Mauritius the Food and Agricultural Research Council estimated that an overall mean of $10 \%$ of orchard lychees were damaged annually by the Mauritian flying fox. Ten trees were studied in each of three orchards, and the mean damage to individual fruit was 2, 7 and 17\% (Aziz et al., 2016). In contrast, a smaller study of four longan Dimocarpus longan trees recorded damage to all fruit panicles. Mangoes (Mangifera spp.) were also damaged at a rate of $10-30 \%$ per year (Aziz et al., 2016). In contrast, a study in a lychee orchard found that high winds and introduced birds, but not bats, resulted in fruit losses of $30 \%$ and 9.5\%, respectively (Ramlugun, 2013).

Netting is regarded as the only effective method for protecting orchards from damage by frugivorous bats, and has been used extensively in Australia (Bicknell, 2002; Ullio, 2002). However, netting is expensive and therefore its implementation is sporadic, although it is cost-effective in the long term. Government subsidies are provided for netting in Australia, Israel and Thailand, and small net bags are used to protect fruit on young trees in Mauritius and Cambodia (reviewed by Aziz et al., 2016). During 2010-2018 MUR 75 million (USD 2.18 million) was spent on the netting subsidy scheme (Agricultural Research and Extension Unit of the Food and Agricultural Research Council, pers. comm.). As data on the damage caused to fruit crops by bats in Mauritius were contradictory and not always collected systematically, we aimed to assess how much damage bats and other animals cause to lychee, mango and longan trees, and evaluated whether netting of trees limits the damage.

\section{Study area}

The study was conducted in Mauritius (Fig. 1), an island of 2 , $011 \mathrm{~km}^{2}$, which has retained $<2 \%$ of its high-quality native vegetation cover and has lost $46 \%$ of its native vertebrate species (Safford, 2001; Cheke \& Hume, 2008). The remaining native wildlife is strongly associated with native vegetation, which has become invaded by exotic species. At least 47 plant species are highly invasive and cause degradation of native habitat. Additionally, numerous exotic animal species cause destruction to native plants and their fruits or seeds, and also spread invasive plant species (Safford, 2001; Cheke \& Hume, 2008). The work was conducted during October 2015-February 2016 in four lychee orchards (Fig. 1), Calebasses, Medine (only large, $>6 \mathrm{~m}$, trees present), Constance, and Belle Vue Maurel (only small, $<6 \mathrm{~m}$, trees present), and at one mango orchard in Labourdonnais. Individual longan trees were assessed in St. Pierre village (Moka region), as there are no longer orchards of this fruit tree in Mauritius.

\section{Methods}

\section{Fruit assessment}

Each orchard in Mauritius typically has trees of various sizes, $1-10 \mathrm{~m}$ in height. We categorized trees as large $(>6$ $\mathrm{m}$ high) or small ( $<6 \mathrm{~m}$ high). Ten small and 10 large lychee trees were chosen randomly and the number of fruits on each tree was assessed by counting the total number of panicles on the tree, using a tally counter, and taking the mean number of fruits per panicle from 20 randomly selected panicles. The total number of panicles was then multiplied by the mean number of fruits per panicle. The same method was applied to longan trees, and mango fruits (given their larger size) were counted individually.

Randomly marked lychee trees were visited daily and the number of fruits on the ground under the trees was assessed 


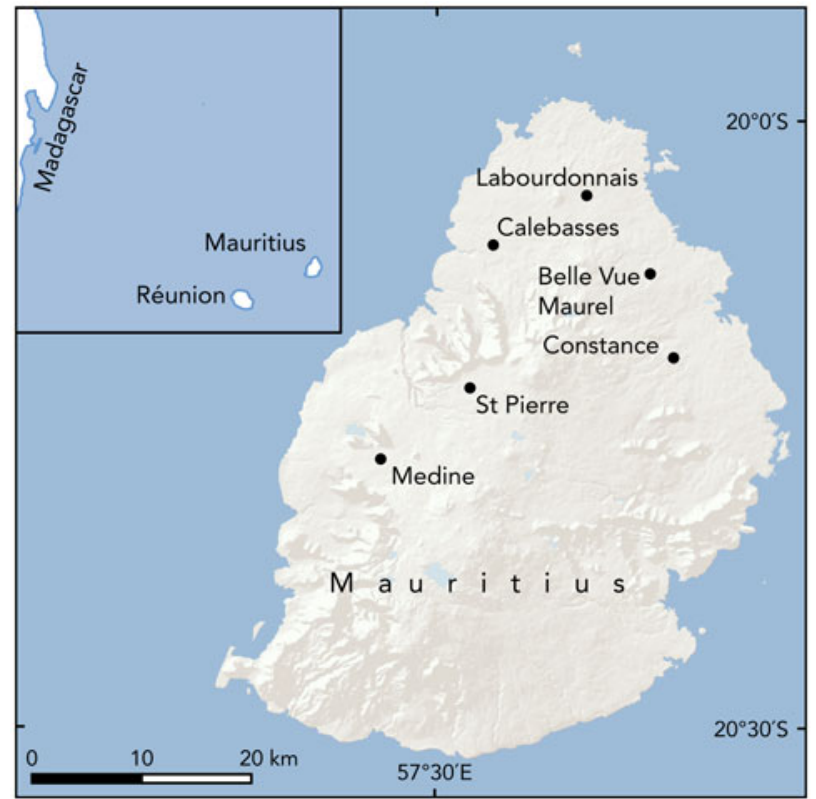

FIG. 1. Locations of the six orchards in Mauritius where the effects of the Mauritian flying fox Pteropus niger on fruit crops were investigated.

and counted. Based on the damage done to the fruits, they were categorized as bat damaged when bat canine marks (triangular shaped puncture wounds) or tooth scrape marks were visible on the fruit or seed; bird damaged when the seed was smooth or the fruit had peck holes in the outer covering, with no visible canine punctures; fungus infected when fruits had breaks in the skin and showed discoloration; rat damaged when marks of incisors were visible on the fruits or seed; and natural fall when intact, undamaged fruits were found on the ground.

It was not possible to make detailed counts of fallen fruits from longan trees because of accessibility problems and their location near roads. Therefore, the number of empty panicles was counted three times per week and damage was attributed to bats and birds combined.

\section{Netting}

In Calebasses lychee orchard three large trees were netted using an anti-bird net (nylon netting with a mesh of $3 \times 3$ $\mathrm{cm}$ ) placed over a frame made of PVC pipes of $50 \mathrm{~mm}$ diameter. The pipes were manipulated over the tree to lift the net above the tree canopy. Three other trees were netted by placing the anti-bird net directly over the tree canopy without frame support. The damage to the netted trees was assessed in the same way as for unnetted trees. Medine lychee orchard had trees already netted, with anti-bird netting placed directly over the tree canopy, with no frame support, so the nets were in direct contact with the trees.
Statistical analyses

Statistical analyses were conducted using $R$ v. 3.4.1 (R Development Core Team, 2017). We used generalized linear mixed models (function glmer in the lme4 package; Bates et al., 2015) to test whether the number of fruits damaged at two lychee orchards (Calebasses and Constance) where both small $(<6 \mathrm{~m}$ high $)$ and large $(>6 \mathrm{~m}$ high) trees occurred (and hence bats had a choice of foraging at large and small trees) differed between the two tree size categories. As only one small tree in the mango orchard was damaged by bats, confidence intervals were large and it was not possible to run a generalized linear mixed model to investigate whether damage varied according to tree size or fruit consumer. Given the nature of the response variable (count data), and to handle overdispersion, we fitted the models with negative binomial distributions. We included the two-way interaction between tree size (large vs small) and causes of fruit loss (bat, bird, rat, fungus, natural fall) as fixed effects in the models, and considered the tree ID nested within the orchard ID as random effects. We used DHARMa (Hartig, 2017) to build diagnostic plots and to validate the model fit. We then identified the most parsimonious model amongst a set of five models that included all possible variable combinations as well as the null model, using the second-order Akaike information criterion (AICc; Burnham \& Anderson, 2002). As our best model was the most complex (interaction between the two predictors; Supplementary Table 1), we conducted post-hoc contrast tests for the pairwise comparisons of interest, adjusting $\mathrm{P}$ values for multiple comparisons using the Tukey method (with package lsmeans; Lenth, 2016).

Bats caused more damage to large than small lychee trees, and therefore we evaluated the effectiveness of using nets on large trees in reducing fruit loss. We conducted separate analyses using generalized linear mixed models with negative binomial distributions for each orchard where the experiment took place (Calebasses and Medine), as different netting treatments were applied. The two-way interaction between netting system (unnetted vs netted without frame vs netted with frame for Calebasses, and unnetted vs netted without frame only for Medine) and causes of fruit loss (bat, bird, rat, fungus, natural fall) were treated as fixed effects, and tree ID was incorporated in the models as a random effect. We applied the same procedure for model validation and selection as described previously (Supplementary Table 1).

\section{Results}

The numbers of trees damaged in each orchard are detailed in Supplementary Table 2 according to fruit type, tree size and fruit consumer at unnetted trees. Lychee trees $>6 \mathrm{~m}$ high produced 2,000-5,000 fruits on average, and trees 
$<6 \mathrm{~m}$ high produced 1,500-4,000 fruits. Bell Vue Maurel was an exception, with trees $<6 \mathrm{~m}$ high producing only 400-900 fruits. There was substantial variation in fruit production among mango trees. Large trees $(>6 \mathrm{~m}$ high) produced $200-6$,000 fruits, whereas small trees $(<6 \mathrm{~m}$ high $)$ produced $200-700$ fruits. Longan trees $(n=10)$ produced a mean of 3,239 \pm SD 2,199 fruits. Overall levels of fruit loss to all causes were substantial $(7-76 \%)$, with three sites having $>50 \%$ fruit damage (Supplementary Table 2).

\section{Bat damage}

At unnetted lychee trees at Calebasses bats damaged 9.4\% of monitored fruit on large trees and $0.1 \%$ on small trees. At Constance bats damaged $15 \%$ of fruits on large trees and $5.3 \%$ on small trees. At Medine bats damaged $52.8 \%$ of fruit on large trees (no small trees were present). Bats damaged $6.7 \%$ of fruits on the small trees at Belle Vue Maurel (no large trees present). At mango trees bats damaged $31.3 \%$ of fruits on large trees and $0.4 \%$ of fruits on small trees. Bat damage was therefore more severe at large trees compared with smaller ones for both lychees and mangos (although statistical analysis was not possible for the latter). This height-dependent effect was significant for bat damage at lychee orchards, but damage by all other agents was not related to tree height (Fig. 2; Supplementary Table 4).

\section{Bird damage}

Birds damaged $3.2 \%$ of fruit on large lychee trees at Calebasses, and $1.5 \%$ on small trees. The equivalent values at Constance were 6.7 and $12.2 \%$, respectively. For the large lychee trees at Medine, $8.3 \%$ of fruits were damaged by birds. For the small lychee trees at Belle Vue Maurel, $6.5 \%$ of fruits sustained bird damage. When large and small lychee trees were present, bird damage was significantly lower than bat damage at large trees, although birds caused more damage than bats at smaller trees (Fig. 2; Supplementary Table 4).

At mango trees birds damaged 13.2 and $50.5 \%$ of fruits on large and small trees, respectively. Damage by birds at small mango trees was therefore substantial and considerably higher than that caused by bats. For longan trees, $32.8 \%$ of fruits were damaged by either birds and/or bats.

\section{Other damage and natural fall}

Damage by rats was negligible ( $<1 \%$ of all fruits). Loss by fungal infection was generally small, although it reached $4-5 \%$ on lychee trees at Constance. Fruit loss by natural fall was typically $<10 \%$ for lychee trees, although it

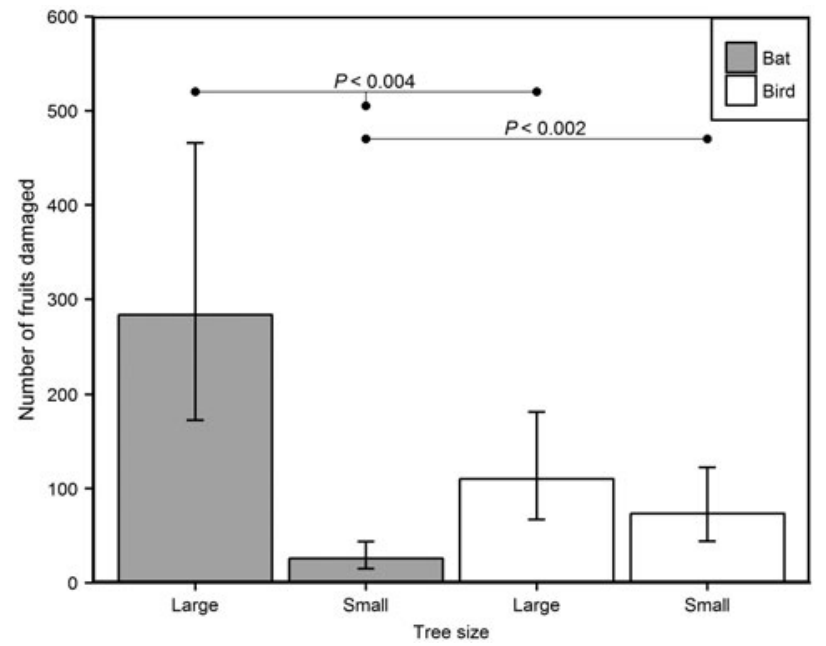

FIG. 2. Predicted means and associated $95 \%$ confidence intervals of number of fruits damaged by bats and birds at large $(>6 \mathrm{~m}$ high; $\mathrm{n}=20)$ and small $(<6 \mathrm{~m}$ high; $\mathrm{n}=20)$ trees in two lychee Litchi chinensis orchards (Calebasses and Constance; Fig. 1). Model predictions arise from the most parsimonious generalized linear mixed model that included the interaction between the cause of damage (bat, bird, fungus, natural fall, rat) and tree size (large, small). P values adjusted for multiple comparisons are given for the pairwise comparisons of interest. The full description of these comparisons is in Supplementary Table 4.

accounted for $26.3 \%$ of total fruits produced by the large mango trees and $50.5 \%$ at the small mango trees studied.

\section{Effects of netting}

The effects of netting were assessed at two lychee orchards, Calebasses and Medine (Supplementary Table 3). At Calebasses bats damaged only $0.4 \%$ of fruits at large trees netted over a frame $(\mathrm{n}=3)$, whereas birds damaged $3.6 \%$ of fruits, compared with $9.4 \%$ bat damage and $3.2 \%$ bird damage at unnetted control sites. The total loss of fruits was $7.7 \%$ for trees netted with frames, compared with $21.4 \%$ at unprotected trees. At the trees netted with no frame $(n=3)$ bats accounted for $0.6 \%$ of damage to fruits, and birds for $3.6 \%$. The total loss was $12.4 \%$ on netted trees with no frame, compared with $21.4 \%$ on unprotected trees. Model predictions (Fig. 3; Supplementary Table 5) indicated that netting both with and without frames at Calebasses significantly reduced fruit damage by bats but had no effect on bird damage. There was no significant difference in damage by bats according to whether the nets were on frames or not.

At trees netted without frames at Medine the damage caused by bats decreased to $12.5 \%$, compared with $52.8 \%$ at unnetted trees (Supplementary Table 3). Birds accounted for $11.5 \%$ of damage at netted trees without frames, compared with $8.3 \%$ at unnetted trees at Medine. Netting trees without frames had no significant effect on bird damage but had a 


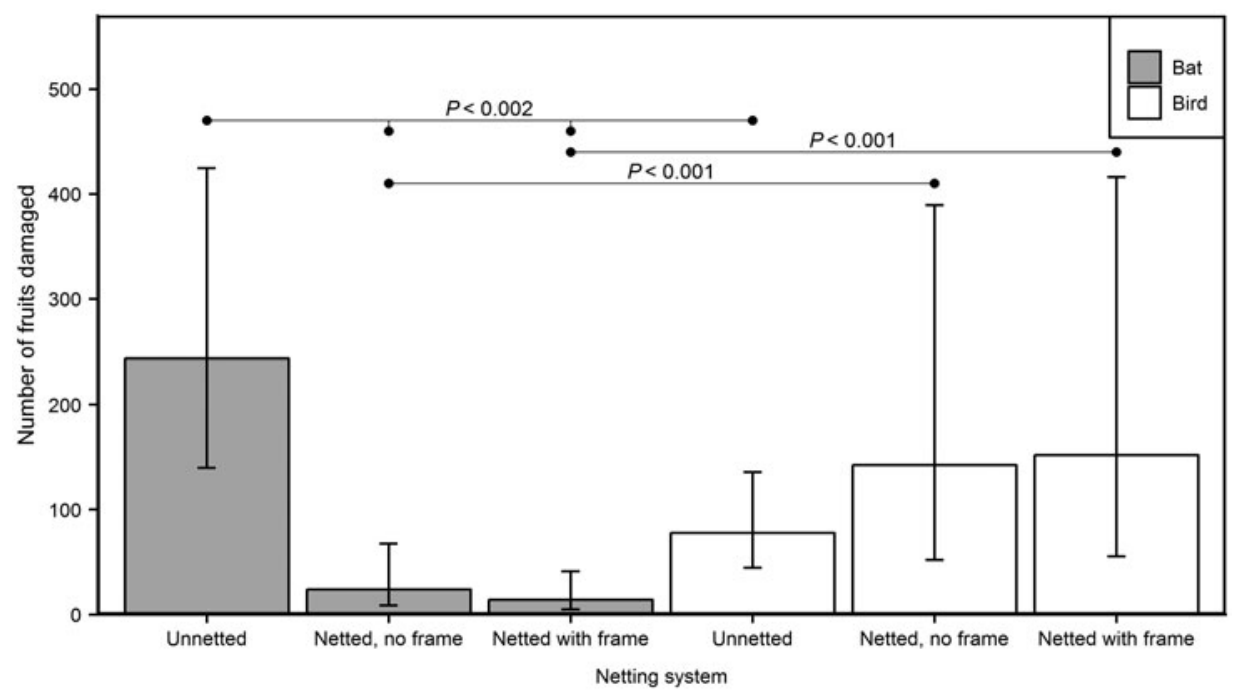

FIG. 3. Predicted means and associated $95 \%$ confidence intervals of number of fruits damaged by bats and birds at large trees in one lychee orchard (Calebasses; Fig. 1) in relation to the netting system implemented: unnetted $(\mathrm{n}=10)$, netted without frame $(\mathrm{n}=3)$, netted with frame $(\mathrm{n}=3)$. Model predictions arise from the most parsimonious generalized linear mixed model that included the interaction between the cause of damage (bat, bird, fungus, natural fall, rat) and the netting system. $\mathrm{P}$ values adjusted for multiple comparisons are given for the pairwise comparisons of interest. The full description of these comparisons is in Supplementary Table 5.

large and significant effect on reducing bat damage (Fig. 4; Supplementary Table 6). The total damage to fruits at Medine was $35.0 \%$ on trees netted without a frame, compared with $69.6 \%$ on unnetted trees.

\section{Discussion}

The damage caused by bats and other animals varies from orchard to orchard. However, small trees $(<6 \mathrm{~m})$ were less prone to damage by bats compared to large trees $(>6$ $\mathrm{m})$. Across the four lychee orchards studied, bats damaged $25.5 \%$ of fruits overall and $1.7 \%$ of fruits at small trees, on average, whereas birds damaged $5.8 \%$ of fruits overall and $4.5 \%$ of fruits at small trees. Bat damage was measured at the trees that we monitored, but bats can potentially carry fruit away to consume it elsewhere. However, from our observations we believe that in general the bats ate fruit at the trees from which they took it, and therefore we believe that our estimates of damage are realistic.

Pruning trees could minimize the impact bats have on fruit crops. However, in places such as Medine and Constance the damage caused by bats was pronounced and even small trees in those orchards suffer substantial fruit losses. Flying foxes often prefer to eat fruits that are too ripe to be sold (Singaravelan et al., 2009), and therefore harvesting the fruit at an earlier stage could also reduce the attractiveness of orchards to bats and other frugivores (Aziz et al., 2016). Up to $10 \%$ of lychee loss in this study was as a result of natural falling of fruit. This loss was even higher at the mango orchard, exceeding $50 \%$ of total fruit at large trees. These losses could potentially be reduced by earlier harvesting.

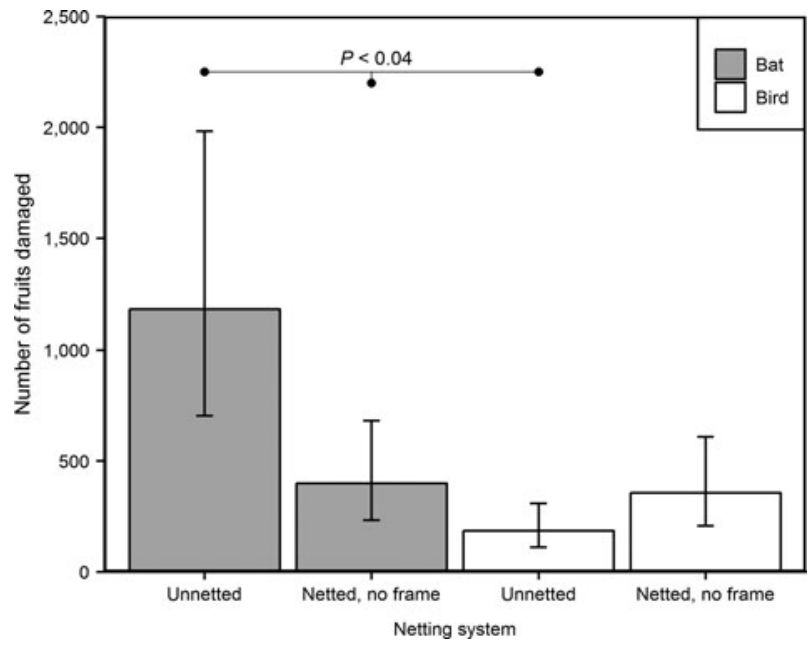

FIG. 4. Predicted means and associated 95\% confidence intervals of number of fruits damaged by bats and birds at large trees in one lychee orchard (Medine; Fig. 1) in relation to the netting system implemented: unnetted $(n=10)$, netted without frame $(n=10)$. Model predictions arise from the most parsimonious generalized linear mixed model that included the interaction between the cause of damage (bat, bird, fungus, natural fall, rat) and the netting system. $\mathrm{P}$ values adjusted for multiple comparisons are given for the pairwise comparisons of interest. The full description of these comparisons is in Supplementary Table 6.

Birds such as the invasive exotic red-whiskered bulbul Pycnonotus jocosus and common myna Acridotheres tristis, and to a lesser extent the ring-necked parakeet Psittacula krameri cause considerably more damage than bats to smaller trees across all the orchards (mango and lychee). Other animals, including rats, were found to have little to no 
impact on the fruits. This could be because rats may feed on fruits that are already on the ground. Fungal infection of lychee fruits is common in Mauritius. However, in all of the orchards assessed, fungicide was sprayed on the trees to protect the fruits against such infection, and loss to fungal infection was minimal.

Netting was successful in reducing the damage caused by bats 16-23-fold in Calebasses and more than 12-fold in Medine, compared with unnetted trees. It is therefore imperative to net trees, preferably using frames so that the net is held above the tree canopy. If nets are placed directly on the trees and in contact with fruits, bats can land on and feed through the net. Additionally, black nets placed directly over the trees are less visible to the bats and as a result bats occasionally becoming entangled in them. To avoid entangling of bats and fruit damage through the net, it is advised to make the net as conspicuous as possible against the tree. Use of white rather than black nets is recommended.

Bird damage on netted trees increased compared with unnetted trees, possibly because birds may become trapped after entering the canopy through gaps in the net. They cause more damage to the fruits in such cases because they continue feeding on them. To avoid gaps, wider nets $(\geq 30 \mathrm{~m})$ than those commonly available in Mauritius (which come in rolls $12 \times 100 \mathrm{~m}$ ) are desirable so that the whole tree can be covered without the need to join nets together, as is the typical practice in Thailand (Aziz et al., 2016). Alternatively, birds may fly under the nets if they are not secured around the base. The ideal is to have fruit trees entirely caged to exclude bats and birds.

In 2017 the Mauritian Government subsidized $75 \%$ of the cost of five nets $(12 \times 10 \mathrm{~m})$ per backyard grower, and $50 \%$ of netting costs for orchards $<0.81$ ha in area (Republic of Mauritius, 2017). Nets typically cost MUR 3,000-3,500 (c. USD 90-100), and are reusable across years if they are stored appropriately. Small-scale fruit growers can potentially recoup the investment in nets, and potentially even the full cost of the nets within the first year of use. The success of the scheme is demonstrable and it has been renewed annually since 2009. However, major orchards in Mauritius may have $>1,000$ fruiting trees, and therefore the subsidy only meets the needs of small-scale growers. In Australia, where orchards can be as large as 90 ha (Aziz et al., 2016), full exclusion netting is used, which gives $100 \%$ protection against bats, birds and abiotic factors. The netting has a mesh size of c. $48 \mathrm{~mm}$, is erected well above the height of the trees and is attached to the ground on the sides. A similar approach is used in Israel on mango, lychee and banana plantations. In many cases the initial reason for using exclusion netting was to reduce water evaporation, as irrigation in Israel is expensive; however, netting ultimately protects the crops against fruit bats and birds. Additionally, the trees are kept low and trimmed regularly, which makes netting easier (authors, pers. obs.). In some orchards in Mauritius, trees are pruned low because it makes them easier to harvest, a practice that should be applied to all mango and lychee trees. Plastic sheets are also used to protect longan orchards in Thailand, and may also accelerate fruit ripening (Aziz et al., 2016). It is likely that large-scale fruit growers in Mauritius may benefit from using netting in orchards even though they do not receive government subsidies, given the substantial reductions in fruit damage resulting from netting, and the relatively low cost of nets.

Currently, apart from netting, growers in Mauritius use a range of other methods, including burning leaves or tyres to create dense smoke, which the bats avoid; installing light bulbs on every tree to illuminate the area and make it less attractive to the bats; and using plastic flags placed above the tree canopy, firecrackers and shotguns to frighten the bats, and in the latter case sometimes to kill them. Additionally, a dead bat may be attached to a bamboo pole and placed over the tree canopy to deter other bats. None of these methods is known to be particularly effective in reducing the impact of bats on fruit, but fruit growers prefer them to netting because they are less time- and labourintensive. Netting is not well accepted by farmers in Mauritius, and it is impractical to net tall trees $(>6 \mathrm{~m}$ high), which are common in backyards.

In Madagascar, Plantskydd deer repellent (Tree World Plant Care Products, Inc., Sechelt, Canada) was tested on lychee trees as a non-lethal taste deterrent against fruit bats (Raharimihaja et al., 2016). The use of this deterrent was compared to waving of red flags and ringing bells. Plantskydd proved to be successful in mitigating bat damage to lychees. However, its composition of dried blood makes its use inappropriate in Mauritius because of religious beliefs and veterinary health restrictions on its import. However, alternative repellents that are not blood-based could be tested. Methods using decoy crops, light or sound, and advancing fruit harvest time may have potential for reducing fruit loss to bats (Aziz et al., 2016).

This work has shown the extent of fruit loss in Mauritian orchards as a result of bird and bat predation and other factors, and is a first step in documenting damage and suggesting solutions. It is important to monitor the orchards for more seasons, to establish the pattern of fruit loss over time. In years when natural food is scarce, bats may be forced to feed more extensively on commercial fruits, whereas during times when native fruits are available the damage may be less pronounced.

In conclusion, we are optimistic that netting fruit trees would reduce the loss of commercial fruit to birds and bats considerably if installed appropriately. The Mauritian Wildlife Foundation continues to promote the benefits of netting to the Government of Mauritius, which reviews and changes its Fruit Protection Scheme regularly, and a strong evidence base exists showing the causes of fruit loss at orchards, and how netting can reduce these losses 
substantially. Culling bats is unnecessary, and unwarranted given that $P$. niger is endemic and vulnerable to mass mortality during cyclones, and provides important ecosystem services, including seed dispersal for native plants.

Acknowledgements The study was conducted in collaboration with the National Park and Conservation Service and the Food and Agricultural Research and Extension Institute in Mauritius. Academic direction and support were provided via the Universities of Bristol and Exeter (UK). The main sponsors of the study were The Rufford Foundation, and the IUCN through a Save Our Species Rapid Action Grant. JSPF was funded by a BBSRC SWBio DTP studentship. We thank all the people of Mauritius who were involved in the study and the data collection, and the fruit growers who allowed us to conduct the study in their orchards. Two anonymous referees provided helpful input.

Author contributions Data collection and analysis: RZO; data collection: CLA; logistical support: VT, CJ; statistical analyses: JSPF; research conception and design, interpretation of the data, academic support and guidance, writing and revision: PAR, GJ; revision and approval of article: all authors.

\section{Conflicts of interest None.}

Ethical standards Our research complies with the Oryx Code of Conduct. The research was conducted under a permit granted by Ministry of Agro-Industry and Food Security in Mauritius (Permit No. 301791; Ref. 2013/M59/I341).

\section{References}

Andrianaivoarivelo, R.A., Jenkins, R.K.B., Petit, E.J., Ramilijaona, O., Razafindrakoto, N. \& Racey, P.A. (2012) Rousettus madagascarensis (Chiroptera: Pteropodidae) shows a preference for native and commercially unimportant fruits. Endangered Species Research, 19, 19-27.

Aziz, S.A., Olival, K.J., Bumrungsri, S., Richards, G.C. \& RACEY, P.A. (2016) The conflict between fruit bats and fruit growers: species, legislation and mitigation. In Bats in the Anthropocene: Conservation of Bats in a Changing World (eds C.C. Voigt \& T. Kingston), pp. 377-426. Springer, New York, USA.

Aziz, S.A., Clements, G.R., McConkey, K.R., Sritongchuay, T., Pathil, S., Aвu Yazid, M.N.H. et al. (2017) Pollination by the locally endangered island flying fox (Pteropus hypomelanus) enhances fruit production of the economically important durian (Durio zibethinus). Ecology and Evolution, 7, 8670-8684.

Bates, D., Mächler, M., Bolker, B.M. \& Walker, S.C. (2015) Fitting linear mixed-effects models using lme4. Journal of Statistical Software, 67, 1-48.

BICKNELL, J.R. (2002) The need for aversion agents for managing flying-foxes on crops and the difficulties in attracting research funds. In Managing the Grey-Headed Flying-fox as a Threatened Species in NSW (eds P. Eby \& D. Lunney), pp. 63-69. Royal Zoological Society of New South Wales, Mosman, Australia.

Bumrungsri, S., Sripaoraya, E., Chongsiri, T., Sridith, K. \& RACEY, P.A. (2009) The pollination ecology of durian (Durio zibethinus, Bombacaceae) in southern Thailand. Journal of Tropical Ecology, 25, 85-92.
Burnham, K.P. \& Anderson, D.R. (2002) Model Selection and Multimodel Inference: A Practical Information-theoretic Approach. Springer, New York, USA.

Cheкe, A.S. \& DAHL, J.F. (1981) The status of bats on western Indian Ocean islands, with special reference to Pteropus. Mammalia, 45, 205-238.

Chere, A.S. \& Hume, J. (2008) Lost Land of the Dodo: An Ecological History of Mauritius, Réunion and Rodrigues. T. \& A.D. Poyser, London, UK.

Epstein, J.H., Olival, K.J., Pulliam, J.R.C., Smith, C., Westrum, J., Hughes, T. et al. (2009) Pteropus vampyrus, a hunted migratory species with a multinational home-range and a need for regional management. Journal of Applied Ecology, 46, 991-1002.

Fleming, T.H. \& KRess, W.J. (2011) A brief history of fruit and frugivores. Acta Oecologica, 37, 521-530.

Florens, F.B.V. (2015) Flying foxes face cull despite evidence. Science, $350,1325$.

Florens, F.B.V., Baider, C., Marday, V., Martin, G.M.N., Zmanay, Z., Oleksy, R. et al. (2017) Disproportionately large ecological role of a recently mass-culled flying fox in native forests of an oceanic island. Journal for Nature Conservation, 40, 85-93.

Fujita, M.S. \& Tuttle, M.D. (1991) Flying foxes (Chiroptera: Pteropodidae): threatened animals of key ecological and economic importance. Conservation Biology, 5, 455-463.

Grant, G.S., Craig, P. \& Trail, P. (1997) Cyclone-induced shift in foraging behaviour in flying foxes in American Samoa. Biotropica, 29, 224-228.

HARTIG, F. (2017) DHARMa: residual diagnostics for hierarchical (multi-level/mixed) regression models. $R$ package version o.1.5. Https://CRAN.R-project.org/package=DHARMa [accessed 8 January 2018].

Izhaki, I., Korine, C. \& Arad, Z. (1995) The effect of bat (Rousettus aegyptiacus) dispersal on seed germination in eastern Mediterranean habitats. Oecologia, 101, 335-342.

Kingston, T. (2016) Cute, creepy or crispy - how values, attitudes, and norms shape human behavior toward bats. In Bats in the Anthropocene: Conservation of Bats in a Changing World (eds C.C. Voigt \& T. Kingston), pp. 571-595. Springer, New York, USA.

Kingston, T., Florens, V., Oleksy, R., Ruhomaun, K. \& Tatayah, V. (2018) Pteropus niger. In The IUCN Red List of Threatened Species 2018: e.T18743A86475525. Http://dx.doi.org/10.2305/IUCN.UK. 2018-1.RLTS.T18743A86475525.en [accessed 16 July 2018].

Lenth, R.V. (2016) Least-squares means: the $R$ package lsmeans. Journal of Statistical Software, 69, 1-33.

Lobova, T.A., Geiselman, C.K. \& Mori, S.A. (2009) Seed Dispersal by Bats in the Neotropics. Memoirs of the New York Botanical Garden 101, New York Botanical Garden, New York, USA.

Pierson, E.D., Elmqvist, T., Rainey, W.E. \& Cox, P.A. (1996) Effects of tropical cyclone storms on flying fox populations on the South Pacific Islands of Samoa. Conservation Biology, 10, $438-451$.

R Development Core Team (2017) R: A Language and Environment for Statistical Computing. R Foundation for Statistical Computing, Vienna, Austria.

Raharimihaja, T.E.A., Rakotoarison, J.L.M., Racey, P.A. \& Andrianaivoarivelo, R.A. (2016) A comparison of the effectiveness of methods of deterring pteropodid bats from feeding on commercial fruit in Madagascar. Journal of Threatened Taxa, 8, 9512-9524.

RAMLugun, T.M.R.R.S. (2013) An assessment of fruit bat damage caused by the Mauritian fruit bat (Pteropus niger) in a lychee (Litchi chinensis) orchard. BSc thesis. University of Mauritius, Mauritius.

Republic of Mauritius (2016). Sixth National Assembly. Parliamentary debates (Hansard). First session Tuesday 31 October 
2017. Http://mauritiusassembly.govmu.org/English/ hansard/Documents/2016/hansardo816.pdf [accessed 12 December 2017].

Republic of Mauritius (2017). Sixth National Assembly. Parliamentary debates (Hansard). First session Tuesday 24 May 2016. Http://mauritiusassembly.govmu.org/English/ hansard/Documents/2017/hansard2317.pdf [accessed 12 December 2017].

S AFFORD, R.J. (2001) Mauritius. In Important Bird Areas in Africa and Associated Islands: Priority Sites for Conservation (eds L.D.C. Fishpool \& M.I. Evans), pp. 385-596. Pisces Publications and BirdLife International (BirdLife Conservation Series No. 11). Newbury and Cambridge, UK.
Singaravelan, N., Marimuthu, G. \& Racey, P.A. (2009) Do fruit bats deserve to be listed as vermin in the Indian Wildlife

(Protection) \& Amended Acts? A critical review. Oryx, 43, 608-613. Ullio, L. (2002) To net or not to net, that is the question! But is it the answer? In Managing the Grey-Headed Flying-fox as a Threatened Species in NSW (eds P. Eby \& D. Lunney), pp. 70-76. Royal Zoological Society of New South Wales, Mosman, Australia.

Vincenot, C.E., Collazo, A.M., Wallmo, K. \& Koyama, L. (2015) Public awareness and perceptual factors in the conservation of endangered species: the case of the endangered Ryukyu flying fox. Global Ecology and Conservation, 3, 526-540.

Vincenot, C.E., Florens, F.B.V. \& Kingston, T. (2017) Can we protect island flying foxes? Science, $355,1368-1370$. 